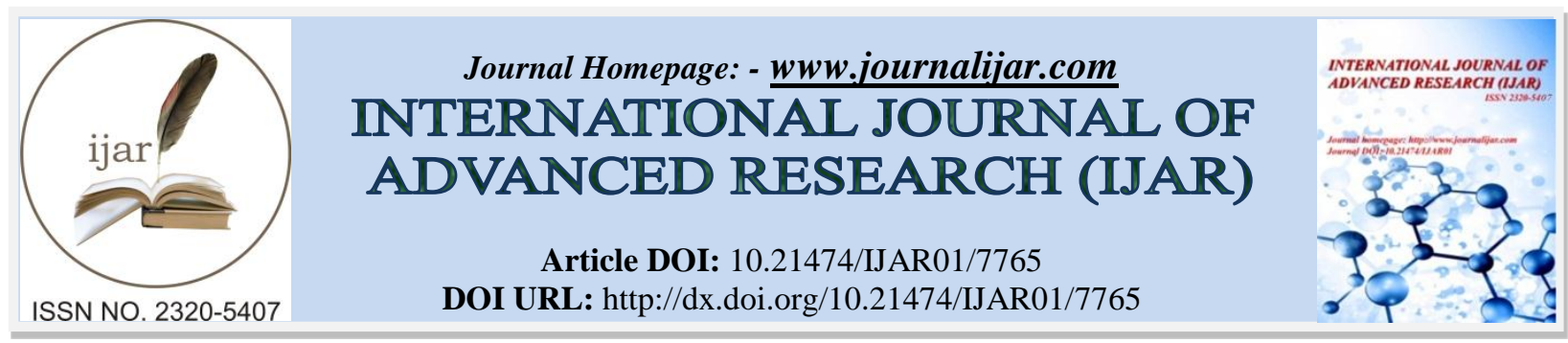

RESEARCH ARTICLE

\title{
IMPACT OF ELECTRICITY SUPPLY ON SUSTAINABILITY OF AGRICULTURE ACTIVITYIN HARYANA.
}

Sunil Kumar.

Research Scholar, Department of Economics, Kurukshetra University, Kurukshetra.

\section{Manuscript Info}

Manuscript History

Received: 25 July 2018

Final Accepted: 31 August 2018

Published: September 2018

Keywords:-

Sustainability, utilization, darkness

\begin{abstract}
The development of the agriculture sector as change for inclusive growth of any economy in the world is very important. At present, numerous of developing and under developing countries, the agriculture sector is generating maximum employment as compared to other sectors. In order to achieve the sustainable development, the agrarian economy has been providing various incentives for accelerating productivity of agriculture sector. Subsidized power supply motivates peoples for utilizing the underground water resources for crop diversification. It has been observed that the crop diversification has been proved conducive to use the irrigation water in a judicious way. However a haphazard use of water has given rise to the depletion of water table, which was experienced in the study area. In other hand, the quality of service has been providing by the companies is very low. The problems like service awareness, power cut, voltage fluctuation, burnout transformer, increase efficient equipment use for save electricity etc. No sufficient efforts have been made by the government to improve the services for the farmers, so that the farmers may motivate to make a proper utilization of electricity and ground water for the sustainable agriculture development.
\end{abstract}

Copy Right, IJAR, 2018,. All rights reserved.

\section{Introduction:-}

Economic development is a key factor to accelerate the progress of the Human Beings. Every country believes in sustainable development. The sustainable development is one of sensitive issue for every human being. In order to attain the sustainable growth in the economy, every sector is playing an important role to participation from progress of the people. In these sectors, agriculture sector is important for developing and under developing countries. At present, this sector is generating maximum employment opportunities as compared to other sectors. The development of the agriculture sector as change for inclusive growth of the economy is reasonable and it has been focused mainly its role in the growth and diversifications of the economy. Indian economy is an agrarian economy, where 60 per cent of people directly or indirectly depend upon agriculture for their livelihood. That is why the agriculture sector is important and the backbone of the Indian economy. In order to develop the agriculture sector, the other factors like electricity and infrastructure play a major role to accelerate the progress of the economy, through subsidized electricity to the farmers. For the agricultural sector, it is widely accepted that an adequate supply of power is pre-requisition for successful implementation of any development strategy. The electricity is widely used as a source of energy. The supply of electricity is highly subsidized by the Government to the 
agricultural sector. It is the Government strategy, so that the farmers may get the remunerative price for their agriculture produces. Electricity is one of the major inputs to use in agriculture activities as role of crops diversification and income generating for the farmer community, as a result, it has expedited the process of economic development. On the other hand, the electricity department has been failed to provide regular and adequate supply of electricity for the farmers. Because the power sector has not given adequate solution related to improvement in the quality of service for agriculture development. An adequate and regular supply of electricity can contribute significantly to develop agriculture sector in a better way. It is very essential to generate financial resources by implementing the policy in an effective way. In addition, an adequate transparency in its functioning as well as an active participation of the people can have the way to make the system more responsive for the executers, belonged to different administrative hierarchy. At present, the electricity is supplied to the farmers, at very subsidies rates by UHBVN and DHBVN, in accordance with the guidelines of the Haryana Electricity Regulatory Commission. The recommendations of HERC, the distribution companies have changed all Un Metered power supply into Metered power supply. The present study is expected to give an adequate insight to highlight different problematic areas of implementation front of subsidized power supply to the agriculture sector. The study also focuses on the consumer's view on power consumption of the farmers. In this context, the views on their awareness on the quality of services and its outcome on diversification of crops, after installation of electric connection on their tube wells in relation to overall sustainable development of agriculture.

\section{The objective of the study}

1. To find the impact of electricity on crop diversifications in the agriculture sector.

2. To examine the quality of service provided for the agriculture sector.

\section{Research methodology}

The study is based on primary, as well as secondary data. The primary data has been collected from the official record of the consumers of powers. The views on various issues on the quality of services provided by the department, on their context, a sample 110 households, representing two districts of Haryana has been chosen. These districts were Rohtak and Bhiwani, which represent UHBVN (Uttar Haryana Bijli Vitran Nigam) and DHBVN (Dakshin Haryana Bijli Vitran Nigam). In order to collect the first hand information, a structured questionnaire has been used to get the desired information. For secondary source of information, various publications of Govt. of Haryana, which include HERC (Haryana Electricity Regulatory Commission), Central Electricity Authority and Power Utilities have also consulted. Haryana State Electricity Board (HSEB) was created by bifurcation of the Punjab State Electricity Board (PSEB in May 1967). HSEB was incorporate as an integrated Utility to discharge the generation, transmission and distribution functions at state level. After implement power sector reforms, the state government was established for regulate power sector an autonomous body name - Haryana Electricity Regulatory Commission. The distribution of electricity was controlled by two companies name Uttar Haryana Bijli Vitran Nigam Limited and Dakshin Haryana Bijli Vitran Nigam Limited. It was observed that physical expansion of electricity transmission is the basis need for sustainable development. According to the geographically characteristics, the state has not been any significant potential to install the hydro power capacity; therefore primarily its focused on thermal power generations to fulfill the energy needs and collaborated with the central power undertakings (CPUs) such as National Thermal Power Corporation (NTPC), National Hydro Power Corporation (NHPC) etc. to installing generation capacity.

\section{Data Analysis and Interpretation}

The total installed generation capacity available with the state as September 2016 was established 8511MW. Out of 81 percent, 16 percent was sourced from Thermal and Hydro power plants respectively. The share of Nuclear and RES sources were merely 1.5 percentages each. The situation of Haryana has been depending upon Thermal power plants. The production cost of Thermal power plants was very higher as compared with other types of power plants. If the government is selling the power in accordance with generation cost, as a result, the poor section of society has been declined in their living standard. That is why, for social justice the government is providing the power on subsidized rate for poor segment of the rural society. On increase of installed generation capacity, the power consumption of agriculture sector has been continuously increased. The Electricity Act, 2003 enacted by the central government had a provision for mandatory metering of supply of electricity and put pressure on states to convert all UN - metered power supply into metered power supply. The low rate of tariffs the power connections on agriculture tube well are rapidly increased in the Haryana. The both Utility has been released the agricultural power connectivity very rapidly. Total AP connections in the state have been increased from 357768 during the year 2001, 
figured 611393 in the year march 2016. But at present time metered power supply connections are increasing other than UN - metered power supply. According to the HERC guidelines, the efficiency framework at present time metered power supply connections are increasing other than Un metered power supply connections. It is because of extensive expansion in the agriculture power connections, the availability of the Agro - Power connections have not been provided by the Utility services in accordance with the demand. After installing the electric tube well, the cost of irrigation of farm has become very low than Diesel Engine tube well. Therefore, the illiterate farmers have caught misguided by middleman of power sector. This is issue to find out through investigation of the field survey. It is therefore imperative to develop the transparency while providing connections to the farmer community. The level of transmission and distribution losses is one of the important indicators to measure the power subsidy on the Government. It has observed that the transmission and distribution losses were high to increased inefficiency to power system. High transmission and distribution losses have been hiked the cost of power supply as well as increase in amount of power subsidy provided by the Government. The periodic data highlights that transmission and distribution losses were consistently decrease gradually. It is important that HERC has pressurized on the distribution companies to improve their efficiency and reduce the energy losses. Subsidy has been criticized on ground of financial burden, but it is beneficial for lower segment of population which is deprived class. Power subsidy is socio economic issue for the developing and under developing economics. Power subsidy is an indirect type subsidy to provide to the agriculture power consumers at the low rate of tariffs by the government through the distribution company. It has been observed that the electricity is consumed by the agriculture sector is based on Un metered and metered power supply, as a result the personnel of the staff do not read the meters in the right way. It is therefore, it become rather different to read the active electric consumption. In this context, the agriculture consumption of electricity is broadly estimated on the residual basis. In practice after deducting the metered consumption of the other sectors from the total supplied. As such there is possibility of adding units of leakage on transmission and distribution loss or line loss and theft. As far as the question of the actual beneficiaries for power subsidy is consumed, it is necessary to note that the farmers, who are benefitted considerably, as a result, it has been observed that the excessive water derived crops, relatively more subsidized. The agriculture power subsidy provided by the Government of Haryana is gradually rising. In order to minimize the burden of agriculture power subsidy, even after the measures taken by the HERC, by installing the meters at their respective farms, the corrupt practices, by the Government officials, has not been stopped. Education is an important indicator to analysis the sample respondents. It was observed that the educated person is to be more effective to determinate for change the living standard. According to the sample one third of total respondents were found under metric. This is a main cause of backwardness of agriculture as compared to other sector in Haryana. In order to examine the quality of service provide by the distribution companies to the agriculture consumers in accordance with some important indicators such as Voltage fluctuation, Power cut, Fault problem and Transformer burnout etc. These indicators indicate the quality of services rendered by the power distribution companies. Voltage fluctuations related problem is considered as an important factor for rural consumers in relation to the services quality received the consumers in rural Haryana. The data clearly shows that the quality of service provide by the Utility service providers is very low level.

Table I:-Company wise classification on Voltage Fluctuations information (\%)

\begin{tabular}{|l|l|l|l|l|}
\hline Particulars & Never & Sometime & Mostly & Always \\
\hline UHBVN & 78 & 22 & 0 & 0 \\
\hline DHBVN & 9 & 36 & 33 & 22 \\
\hline OVERALL & 44 & 29 & 16 & 11 \\
\hline
\end{tabular}

Source: field survey, 2016.

On the basis of analysis of deserved data, which indicate that 66 percent of consumers who have pointed out that there is voltage fluctuations during the supply hours. This problem has been found relatively higher in DHBVN than UHBVN. It is because of voltage fluctuations which have created the problem related of there were burning of motor, transformer and cables. As a result, frequent financial loss for the farmers. Another problem of power cut, during the supply hours indicate the worst form of quality of service. All these problematic areas indicate a low level of satisfaction for the services, rendered by the power distribution companies. However, it was justified with the findings of the study.

Table II:-Distribution of Companies in accordance with power cut problem (\%)

\begin{tabular}{|l|l|l|l|l|}
\hline Particulars & Never & Sometime & Mostly & Always \\
\hline UHBVN & 0 & 7 & 71 & 22 \\
\hline
\end{tabular}




\begin{tabular}{|l|l|l|l|l|}
\hline DHBVN & 0 & 20 & 58 & 22 \\
\hline OVERALL & 0 & 14 & 64 & 22 \\
\hline
\end{tabular}

Source: field survey, 2016.

According to the sample survey there were 64 percent of respondents, who have reported that the majority of the respondents were satisfied very low level. As most of the respondents have pointed out that the power cut problem on the supply hours was very crucial, as faced by the agriculture consumers. The maintenance related problem such as fault and transformer burnout problem indicate the deteriorated quality of services. It was expected to lower the solve time related to the maintenance problem, higher the satisfactions level of consumers within the quality of service providing by the Utility.

Table III:-Distribution of companies in accordance with solution of the fault problem

\begin{tabular}{|l|l|l|l|}
\hline Particulars & $0-6$ Hours & $6-12$ Hours & Above12 Hours \\
\hline UHBVN & 0 & 85 & 15 \\
\hline DHBVN & 26 & 47 & 27 \\
\hline OVERALL & 13 & 66 & 21 \\
\hline
\end{tabular}

Source: field survey, 2016. * Days in percentage

The table III indicates that there were 85 per cent of UHBVN, 47 per cent of DHBVN and Overall 66 percent of agriculture consumers were "say 6-12 hours" to solve the problem of fault. It is a one of main issue for both the service providers. This type of problem has been become main problem which affect the agricultural productivity as well as the economic conditions of the farmers. Thus, it become a necessity of maintenance of transformers for the consumers, belongs to agricultural activities. For the agriculture production, it is very important to timely irrigate the crops. Otherwise, it will affect the quality of agriculture produce, as a result prone to get lesser price for their produce. Therefore, the farmer is facing numerous economical problems after wastage of crops. It is therefore, it become imperative to create awareness for maintenance of the transformers, so that qualitative services are provide to the farmers.

Table IV:-Distribution of company wise solution of Transformer problem

\begin{tabular}{|l|l|l|l|l|}
\hline Particulars & $1-7$ Days & $7-15$ Days & $15-30$ Days & Above 30 Days \\
\hline UHBVN & 2 & 2 & 89 & 7 \\
\hline DHBVN & 11 & 35 & 45 & 9 \\
\hline OVERALL & 7 & 18 & 67 & 8 \\
\hline
\end{tabular}

Source: field survey, 2016. * Days in percentage.

The table IV shows that there were 67 per cent consumers were reported to "say 15 - 30 days" solution of transformer maintenance. There were 89 per cent of the respondents belonged to UHBVN and 45 per cent of the respondents belonged to DHBVN consumers have reported to "say 15 - 30 days" solution of transformers maintenance. It has been observed that the consumer's belonged to service provider, belonged to DHBVN consumer lesser time to solve the problem of maintenance of the transformers.

Haryana is an agriculture based economy. Therefore, this study is based on agriculture power subsidy. In the study it was observed that the main source of irrigation is the ground water, taken for the study. On the basis of the study, carried out on the respondents, belonged to farmer's community, make use of Tube Well, as a source of irrigation. As a result, a considerable change in cropping pattern has been observed from food grain to cash crops. In order to examine the agricultural productivity various powers related factors have been analyzed. In this context, various suggestions have been recommended for further improvement in the cropping pattern. 
Figure I:-Company wise comparison changing of Cropping Pattern before and after installation of Tube Well in area (Acre)

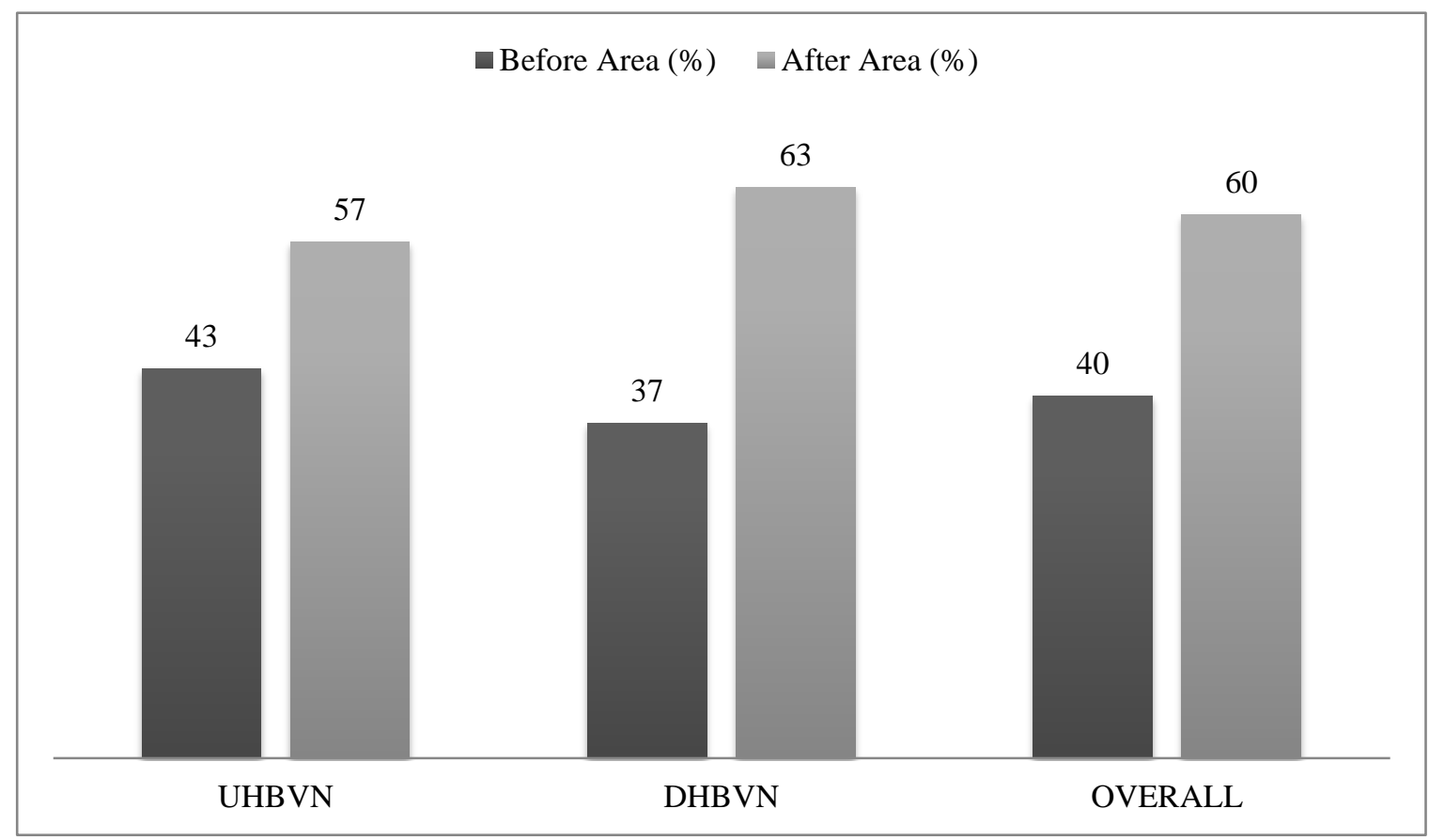

Source: field survey, 2016. * Area in percentage

Keeping in view the graphical figures, it has been observed that there is a considerable growth in operating land holdings. It has been noticed that the change has been taken place before and past installation of tube wells. In case of UHBVN, the growth has been experienced from 43 per cent to 57 per cent. On the other hand, the corresponding figures indicate a growth from 37 percent to 63 per cent as shown by DHBVN during before and past installation of tube wells. A total growth in land holdings has been experienced from 40 per cent to 60 per cent in the study area. It is therefore, suggested that there is more probability to increase the cover land under tube well to increase their production of their agriculture. In the context, a seasonal variability has also been observed in accordance with installation of tube wells for changing pattern of crop combination. There are two crop seasons, rabi and kharif, which start in beginning of winter and late summer respectively. A season - wise analysis of the crop's variability, it has been observed that changing cropping pattern is determined by the installation of tube wells in the changing seasons. 
Figure II:-Comparison of Cropping Pattern in accordance with before and after installation of Tube Well in Kharif Season

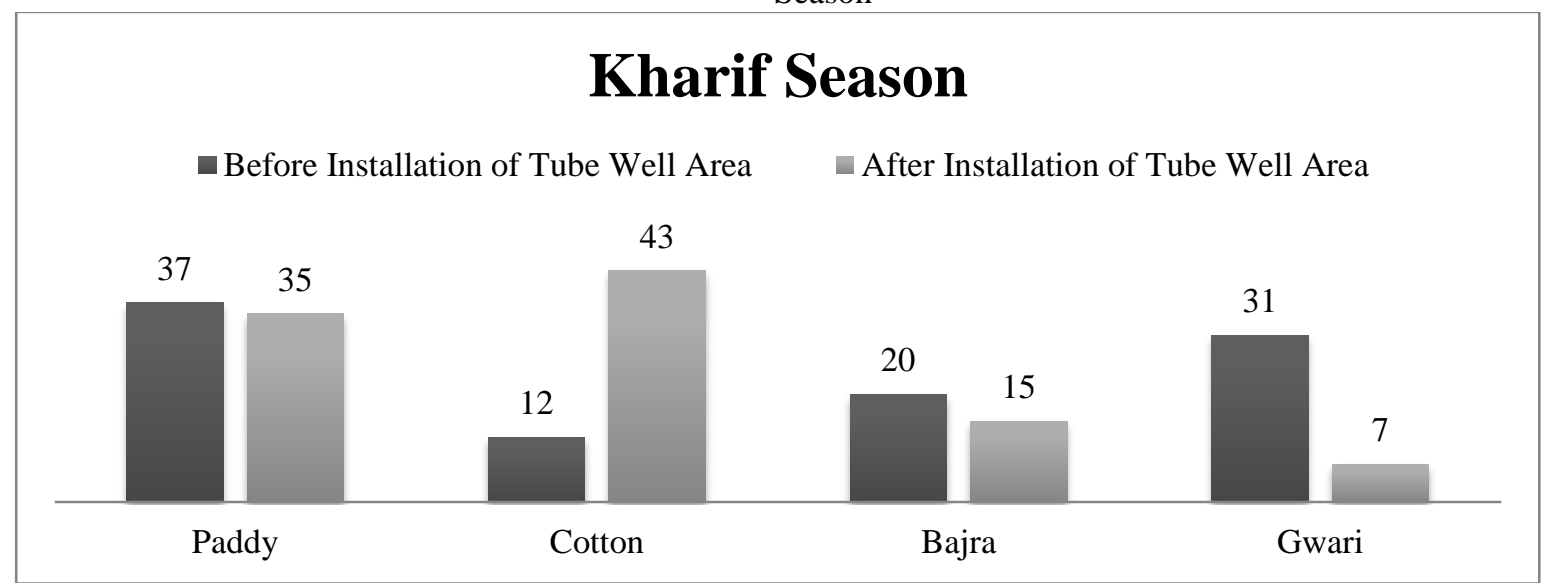

Source: field survey, 2016. * Area in percentage.

Keeping in view the graphical figures, we may observe that the area under Paddy cultivation has been declined by 2 percent, with the result of before and after the installation of tube wells. The main reason behind this decreasing trend of area under rice cultivation has been experienced a considerable fluctuation of MSP (Minimum Support Price) of rice since last year. On the other hand, the MSP of sugarcane has shown a considerable increasing trend during that year. The dry land areas have been facilitated with assured irrigation by different mode of irrigation. In case of Bajra and Gwari, it shows a declining trend where the tube wells have been installed by the farmers. The main reason was behind this change in cropping pattern has been the priority given by the farmers. The farmers now preferred cash crop like rice and cotton after installation of tube wells in their respective fields. As a result, they have successfully raised their standard of living.

Figure III:-Distribution of comparative figures of different Cropping Pattern during before and past installation of Tube Wells in Rabi Season

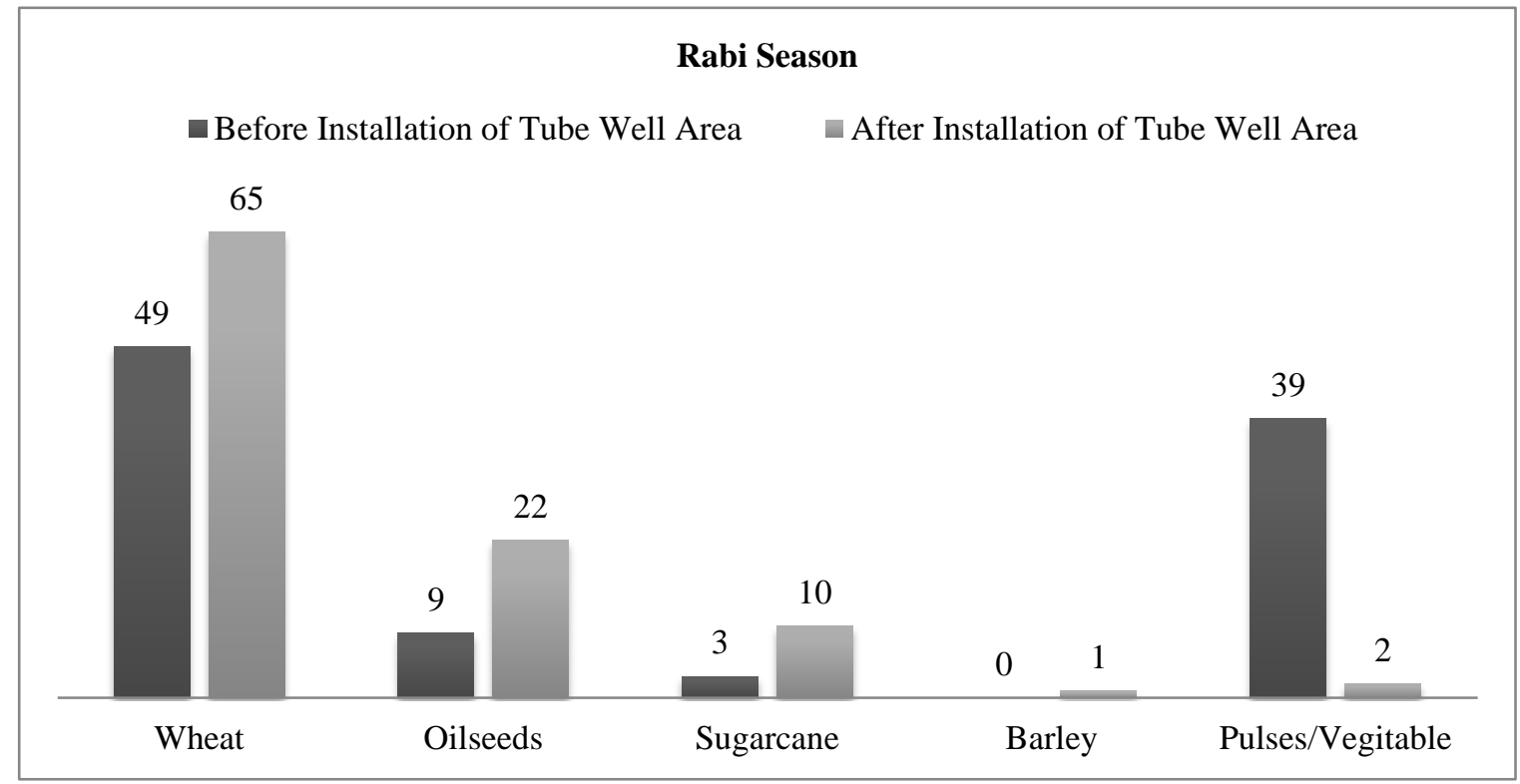

Source: field survey, 2016. * Area in percentage.

Keeping in view the graphical figures of different Rabi crops, it has been observed that the wheat has been shown increasing trend amongst the Rabi crops. It has been observed that there had been 16 percent growth experienced by the wheat due to installation of tube wells in their respective fields. The area under wheat has been increased in the district Bhiwani as installed tube wells within the district Bhiwani increases. However, the irrigation requirement for 
the wheat crop is 5 to 10 irrigations, which was fulfilled by the installation of tube wells in the Bhiwani district. In case of oil seeds production, it has been observed that the production of oil seeds has been increased by 13 percent. It is because of installation of tube wells in the district. In case of sugarcane production, it has been observed that the production of sugarcane has been increased by 7 percent, after the installation of tube wells, by the farmers, belonged to district Rohtak. The tube well water is relatively cost effective, as compared with the diesel operated pump sets. Similarly, the growth of barley has also been shown increasing trend. In case of vegetable production, it has been observed that there has been considerable of growth of vegetable too. It is because of supporting the price of the vegetables by the government, and partly the change in preference, made by the farmers in both the districts. The cropping pattern has a vital significance, which is a result of changing the priority, price and seasonal change in demand of the local market, as justified by the observed data, taken for the study. On the basis of the results, this shows that there were 96 percent of UHBVN and 82 percent of DHBVN. The overall, there were 89 percent of the respondents, which has been facilitated by the tube wells for ensuring the irrigation facility in the dry land areas of both the districts. The other factors, which include the factors of MSP given by the government, crop diversification and the credit services, facilitated by the commercial and cooperative banks, cumulatively paved the way to raise the production and productivity of various crops in both the districts.

\section{Concluding Remarks}

On the basis of drawing the inferences from the observed data, which indicate a considerable variability in execution process of directed changes, brought by the respondents, belonged to different consumers. The factors like subsidies on electricity, chemicals, fertilizers etc. have been playing a very significant role in changing pattern of crops during recent years. In this context, it has also been considered that the factors like weather conditions, awareness of the people, supply of power and the preference made by the farmers etc. have been playing a vital role to determine the changing behavior of the farmers to change the cropping pattern of the kharif and rabi crops in the district taken for the study. Though a considerable growth in varied crops have been experienced during different successive periods, but the fluctuation of the prices of the agricultural produce have not been supported by the factors like demand and supply of the grains, from time to time. However, it has been affected by the number of tube wells, installed by the farmers, belonged to different hierarchies. Secondly, the man - illiteracy among the farmers, as a result, they have been misguided by the middlemen of the power sector too. Thirdly, the loss of power in transmit ion, which has given rise to increase their cost of production, which deserve a special attention to correct it in accordance with changing scenario. Investment in human development is a vital significance, so that a judicious growth way takes place in the agricultural production by taking preventive and curative steps to make efficient use of natural and manmade resources for the welfare of the farmer's community, so that a sustainable development may take place in the state.

\section{References:-}

1. Ahluwalia S. Sanjeev, "Power tariffs Reform in India", Economic and Political Weekly, Vol. 35, No. 27 - 30, PP. 33 - 39, September 16,2001.

2. Badani, Reena, K. Jessoe, Katrina, "Electricity Subsidies for agriculture: Evaluating the Impact and Persistence of these Subsidies in India”, Draft Report available //www.ncsu.edu/cenrep/workshops/TREE/documents/Jossoe_electric.pdf, 2011.

3. GOH, Statistical Abstract of Haryana (various issue), Planning Department, Govt. of Haryana, Chandigarh.

4. GOI, Ministry of Power, Central Electricity Authority, New Dehli, Executive Summary Power Sector, March, 2015.

5. Gulati Ashok, "Input Subsidies in Indian Agriculture: A State - wise Analysis", Economic and Political Weekly, Vol. 24, No. 14 - 26, June 24, 1989.

6. Gulati Ashok, Sharma Anil, "Subsidy Syndrome in Indian Agriculture”, Economic and Political Weekly, PP. 93 - 102, September 30, 1995.

7. Howes Stephen, Murgai, Rinku, “Incidence of Agricultural Power Subsidies”, Economic and Political Weekly, PP. 1533 1535, April19, 2003.

8. Kumar, Rajesh, "Role of IT in Power Sector: An Innovative Tool to Empower Consumers", Indian Power, Vol. XVII, No. 1, PP. 28 - 32, January - March, 2009.

9. Monari, Lucio, "Power Subsidies", view note available online www.worldbank.org/viewpoint/india, Note Number 244, April, 2002.

10. Murthy Ramachandra, K.V.S., and Raju Ramalinga, M.,“Analysis on Eectrical Energy Consumption of Agricultural Sector in Indian Context”, ARPN Journal of Engineering and Applied Sciences, Voi. 4, No. 2, April, 2009.

11. Narendranath,G., Shankari Uma, Reddy, Rajendra k. (2005), "To Free or Not to Free Power: Understanding the context of free power to Agriculture". Economic and Political Weekly, PP. 5561 - 5570, December 31.

12. Pachauri, R.K. (1998), "Economics of Energy Use in Agriculture”, Indian Journal of Agricultural Economics, Vol. - 53, No. 3, July - September. 
13. Reddy, K.S., (1992), "Who Benefits from Agricultural Subsidies?: The case study of Andhra Pradesh”, Margin, Vol. 25, No. 1 , October - December.

14. Sant, Girish, Dixit shantanu (1996), "Beneficiaries of IPS Subsidy and Impact of Tariff

Hike". Economic and Political Weekly, PP. 3315 - 3321, December 21.

15. World Bank, (2001), India Power Supply to Agriculture, (Vice President: Mieko Nishimizu), Vol. - 1, summary report, Energy Sector Unit, South Asia Regional Office. 